\title{
Effectiveness of a pre-procedural mouthwash in reducing bacteria in dental aerosols: randomized clinical trial
}

\section{Belén RETAMAL-VALDES(a) \\ Geisla Mary SOARES(a) \\ Bernal STEWART ${ }^{(b)}$ \\ Luciene Cristina FIGUEIREDO(a) \\ Marcelo FAVERI (a) \\ Steven MILLER ${ }^{(b)}$ \\ Yun Po ZHANG(b) \\ Magda FERES(a)}

(a) Universidade de Guarulhos, Department of Periodontology, Dental Research Division, Guarulhos, São Paulo, Brazil.

(b) Colgate-Palmolive Company, Piscataway, NJ, USA.

Declaration of Interests: Bernal Stewart, Steven Miller and Yun Po Zhang are currently employed by Colgate Palmolive Company. The other authors certify that they have no commercial or associative interest that represents a conflict of interest in connection with the manuscript.

Corresponding Author:

Magda Feres

E-mail:mferes@ung.br

https://doi.org/10.1590/1807-3107BOR-2017.vol31.0021

Submitted: Sep 26,2016

Accepted for publication: Jan 24, 2017

Last revision: Feb 06, 2017

\begin{abstract}
The aim of this randomized, single blinded clinical trial was to evaluate the effect of a pre-procedural mouthwash containing cetylpyridinium chloride (CPC), zinc lactate $(\mathrm{Zn})$ and sodium fluoride $(\mathrm{F})$ in the reduction of viable bacteria in oral aerosol after a dental prophylaxis with ultrasonic scaler. Sixty systemically healthy volunteers receiving dental prophylaxis were randomly assigned to one of the following experimental groups (15 per group): (i) rinsing with $0.075 \%$ CPC, $0.28 \%$ $\mathrm{Zn}$ and $0.05 \% \mathrm{~F}(\mathrm{CPC}+\mathrm{Zn}+\mathrm{F})$, (ii) water or (iii) $0.12 \%$ chlorhexidine digluconate (CHX), and (iv) no rinsing. Viable bacteria were collected from different locations in the dental office on enriched TSA plates and anaerobically incubated for 72 hours. The colonies were counted and species were then identified by Checkerboard DNA-DNA Hybridization. The total number of colony-forming units (CFUs) detected in the aerosols from volunteers who rinsed with $\mathrm{CPC}+\mathrm{Zn}+\mathrm{F}$ or $\mathrm{CHX}$ was statistically significantly $(p<0.05)$ lower than of those subjects who did not rinse or who rinsed with water. When all locations were considered together, the aerosols from the $\mathrm{CPC}+\mathrm{Zn}+\mathrm{F}$ and $\mathrm{CHX}$ groups showed, respectively, 70\% and $77 \%$ fewer CFUs than those from the No Rinsing group and $61 \%$ and $70 \%$ than those from the Water group. The mean proportions of bacterial species from the orange complex were statistically significantly $(p<0.05)$ lower in aerosols from the $\mathrm{CPC}+\mathrm{Zn}+\mathrm{F}$ and $\mathrm{CHX}$ groups compared with the others two groups. In conclusion, the mouthwash containing $\mathrm{CPC}+\mathrm{Zn}+\mathrm{F}$, is effective in reducing viable bacteria in oral aerosol after a dental prophylaxis with ultrasonic scaler.
\end{abstract}

Keywords: Cetylpyridinium; Chlorhexidine; Aerosols; Mouthwashes; Microbiology.

\section{Introduction}

The propagation of oral microorganisms in the dental office during different oral procedures has been a concern. The use of certain equipment such as ultrasonic devices, ${ }^{1,2,3,4,5}$ highspeed dental handpieces ${ }^{6,7}$ or three-way syringes ${ }^{8}$ may spread aerosols and splatters containing microorganisms in the environment. These microorganisms may cause cross-infections in the dental office, jeopardizing the health of patients and dental professionals. ${ }^{9}$

Different procedures, materials and antimicrobial agents have been proposed to minimize microbial cross-contamination in the dental office, 
such as immunization of dental staff, decontamination of surfaces, sterilization of instruments, use of personal protective barriers and pre-procedural mouthwashes. ${ }^{910,11,12}$ Chlorhexidine (CHX) is considered the gold standard substance in controlling oral biofilm growth in the oral cavity or microbial spread by oral aerosols ${ }^{3,4,9,13,14,15}$ due to its broad antibacterial spectrum $^{14,16}$ and substantivity of 8 to 12 hours. $^{14}$ However, other antiseptics have also been used as pre-procedural mouthwashes, such as essential oils ${ }^{17}$ and cetylpyridinium chloride (CPC).,15 $\mathrm{CPC}$ has an important antimicrobial activity ${ }^{18,19}$ and is considered a safe product for marketing. ${ }^{20}$

The authors of this study have previously demonstrated the effectiveness of a pre-procedural mouthwash containing CPC in reducing viable bacteria in dental aerosol after a prophylaxis with an ultrasonic scaler. This study introduced CPC as a good alternative to $\mathrm{CHX}$, due to its effective antibacterial action, fewer adverse effects and lower cost. ${ }^{3}$ In addition, a recent clinical study has indicated that a higher concentration of $\mathrm{CPC}-0.07 \%$, is very effective in controlling plaque accumulation and gingivitis, ${ }_{1}^{18}$ however, to date no studies have evaluated the effectiveness of CPC at this higher concentration as a pre-procedural mouthwash.

The present trend has been to combine more than one active substance in mouthwash and toothpaste formulations with the aim of increasing the efficacy of the products, or treating more than one clinical problem, such as plaque accumulation and halitosis, ${ }^{21,22}$ caries $^{23}$ or gingival inflammation. ${ }^{24}$ Following this line of thought, zinc has been added to some oral hygiene products due to its good antimicrobial and anti-inflammatory properties ${ }^{25}$ and its capacity of neutralizing volatile compounds that play an important role in halitosis. ${ }^{21,26}$ Similarly, fluoride has been added to mouthwashes formulations due to its effect in caries prevention ${ }^{23}$ and in dental remineralization. ${ }^{27}$ Based on this body of evidence, the aim of this study was to evaluate the effectiveness of a mouthwash formulation containing $0.075 \%$ CPC, $0.28 \%$ zinc lactate and $0.05 \%$ sodium fluoride $(\mathrm{CPC}+\mathrm{Zn}+\mathrm{F})$, in reducing viable bacteria present in oral aerosol/splatter.

\section{Methodology}

\section{Sample size calculation}

The ideal sample size to assure adequate power for this study was calculated based on the data of Feres et al. ${ }^{3}$ Considering a difference of at least 682 CFUs between groups $\mathrm{CPC}+\mathrm{Zn}+\mathrm{F}$ and Water and assuming a standard deviation of 435 , it was defined that 15 subjects per group is adequate to provide a $95 \%$ power with an $\alpha$ of 0.05 .

\section{Subject population}

Systemically healthy volunteers were selected from the population referred to the Center for Clinical Trials at Guarulhos University (Guarulhos, SP, Brazil). The medical and dental histories were obtained and a full-mouth periodontal examination was performed. The study protocol was explained to each volunteer and those who met the inclusion/exclusion criteria, signed the term of Free and Informed Consent, filled out a health questionnaire, and were enrolled in the study. The study protocol was previously approved by the Guarulhos University Ethics Committee on Clinical Research (CAAE: 41244315.4.0000.5506). The ClinicalTrials.gov identifier of the present study is NCT02875769.

\section{Inclusion criteria}

The inclusion criteria were as follows: male or female aged between 18-70 years, minimum of 20 natural teeth, at least $80 \%$ of the sites with visible supragingival plaque, fewer than $10 \%$ of sites with visible supragingival calculus, fewer than $30 \%$ of sites with probing depth $(\mathrm{PD}) \geq 5 \mathrm{~mm}$.

\section{Exclusion criteria}

The exclusion criteria were as follows: presence of orthodontic bands; partial removable dentures; lesions of the soft or hard tissues of the oral cavity; carious lesions requiring immediate restorative treatment; history of allergy to $\mathrm{CHX}, \mathrm{CPC}$, zinc lactate or sodium fluoride; participation in any other clinical study within the one-month period prior to entering into the study; professional tooth cleaning procedure (oral prophylaxis) during the period of one month prior to entering the study; pregnant or breast-feeding 
women; antibiotic therapy in the previous 6 months; continuous use of oral mouthwashes and any systemic condition that may require prophylactic medication for dental treatment (e.g., mitral valve prolapse).

\section{Clinical assessment}

In order to select the volunteers for the study, one trained periodontist (G.M.S.) performed a clinical examination that included an oral tissue evaluation and periodontal assessment. The oral examination included an evaluation of the soft and hard palate; gingival mucosa; buccal mucosa; mucogingival fold areas; tongue, sublingual and submandibular areas; salivary glands, and the tonsilar and pharyngeal areas. Visible plaque (0/1) and PD ( $\mathrm{mm})$ were measured at six sites per tooth (mesiobuccal, buccal, distobuccal, mesiolingual, lingual and distolingual) in all teeth, excluding third molars. The PD was recorded to the nearest millimeter using a North Carolina periodontal probe (Hu-Friedy, Chicago, IL, USA). The volunteers have refrained from any oral hygiene procedure for twelve hours prior to the clinical examination, and from eating, drinking or smoking for four hours prior to the examination.

\section{Experimental design, randomization, allocation concealment and treatment protocol}

In this single blinded randomized clinical trial (RCT), using simple randomization and a 1:1 allocation ratio, the study coordinator (L.C.F.) used a computer-generated table to randomly assign the volunteers to the following groups ( $n=15$ per group): 1- CPC $+\mathrm{Zn}+\mathrm{F}$ (test): mouthwash containing $0.075 \%$ CPC, $0.28 \%$ zinc lactate and $0.05 \%$ sodium fluoride in an Alcohol-free base; 2- Water (negative control): water from a three-way syringe; 3- $\mathrm{CHX}$ (positive control): $0.12 \%$ CHX with $10 \%$ alcohol; 4 - No Rinsing (negative control): standard of care - no rinsing.

In an unoccupied dental office, previously cleaned with detergent, alcohol and sodium hypochlorite, in which no regular patients had been treated on that day, the study coordinator placed five plates containing Tryptic Soy Agar with Yeast Extract enriched with 5\% menadione, $5 \%$ sheep blood, and $1 \%$ N-Acetylmuramic acid (HNK plates) to sample microorganisms contained in the unit atmosphere. Three plates were placed on a support board attached to the reflector, which had been previously designed ${ }^{3}$ for this type of experimental design, one on the bracket tray, and another on the office bench (Figure 1). The room was locked and after 30 minutes, the plates were closed and labeled properly and sent to the laboratory for incubation. Subsequently, the volunteers were invited to sit on the dental chair to proceed with the first phase of the study. A researcher, who did not participate in any of the other phases of the study (B.R.V.), checked the randomization list containing the names of the Water and No Rinsing groups, and codes for $\mathrm{CPC}+\mathrm{Zn}+\mathrm{F}$ and $\mathrm{CHX}$ groups, and selected the solutions for the volunteers from groups $\mathrm{CPC}+\mathrm{Zn}+\mathrm{F}, \mathrm{CHX}$ and Water. $\mathrm{CPC}+\mathrm{Zn}+\mathrm{F}$ and $\mathrm{CHX}$ mouthwashes were placed in identical opaque coded flasks, which assured the allocation concelament for these two groups, but not for the Water and No Rinsing groups. The researcher entered the dental office and handled one of three solutions to the volunteer, who rinsed for one minute with $20 \mathrm{ml}$ of the solution and then expectorated the remaining liquid. The clinician (G.M.S.) did not participate on this phase of the study, and only entered the office after the rinsing phase had been completed. The volunteers were instructed to not mention to the clinician whether or not they had rinsed with a given solution. These procedures assured the masking of the clinician (G.M.S.) and the allocation concealment of the study.

After this phase, one volunteer at a time was reclined to a supine position and three new HNK agar plates were placed on the support board, one on the volunteer's chest (immediately in front of the volunteer's mouth) and one on the clinician's forehead. Subsequently, the study coordinator opened the plates and the clinician proceeded with the full mouth dental prophylaxis using an ultrasonic scaler at a frequency of $25 \mathrm{kHz}$ (Cavitron Select, Dentsply, York, Pa) at less than $50 \%$ power for 10 minutes. After the oral prophylaxis was completed, the five HNK agar plates were covered, labeled and sent to the laboratory for incubation. Volunteers were dismissed from the dental room. The dental office was then cleaned and disinfected with detergent, alcohol and sodium hypochlorite and the next subject was attended at least 5 hours later. 


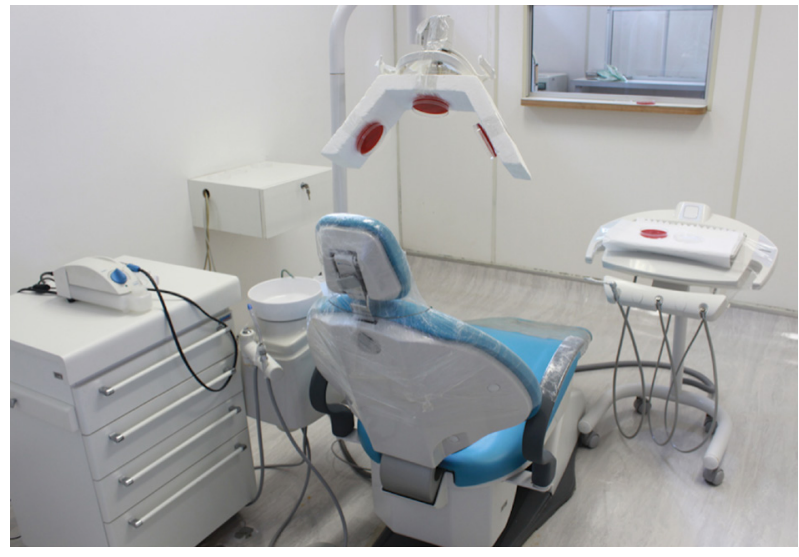

Figure 1. Microbial sampling technique used to evaluate the presence of microorganisms in the dental office before prophylaxis with an ultrasonic scaler.

\section{Microbiological procedures}

a. Microbial quantification: the HNK plates were incubated under anaerobic condition in jars containing $10 \% \mathrm{CO}_{2}$ at $37^{\circ} \mathrm{C}$ for 72 hours under anaerobic conditions, using the BD GasPak EZ system (Becton Dickinson, Sparks, MD). Using a Lab Line Colony Counter (Phoenix model CP $600 \mathrm{~N} 302)$, a laboratory technician counted the colony-forming units (CFUs). For this purpose, the technician was calibrated using the kappa test and a value of $90 \%$ was obtained and accepted. The technician was not aware of which plates were exposed to each treatment.

b. Microbial identification: after counting, the colonies were washed off the agar plates. The technician added $1 \mathrm{ml}$ of TE buffer $(\mathrm{pH}=7.6)$ to the plates and the bacterial colonies were scraped off the surfaces using L-shaped Pasteur pipettes. The suspensions were placed in individual Eppendorf tubes and sonicated for 10 seconds (Analyzer model SP 2000 UV) and the optical density (OD) at $700 \mathrm{~nm}$ of each suspension was adjusted to a final value of 1.0, corresponding to approximately $10^{9}$ bacterial cells/ml. After this, 10 ul of each suspension was removed and placed in another Eppendorf tube and $140 \mathrm{ul}$ of TE buffer and $100 \mathrm{ul}$ of $0,5 \mathrm{M} \mathrm{NaOH}$ were added. The samples were analyzed for 40 oral bacterial species using the Checkerboard DNA-DNA Hybridization technique. ${ }^{28,29}$ c. Checkerboard DNA-DNA hybridization: the samples were boiled for $10 \mathrm{~min}$. and neutralized using $0.8 \mathrm{ml}$ of $5 \mathrm{M}$ ammonium acetate. The released DNA was then placed into the extended slots of a Minislot 30 apparatus (Immunetics, Cambridge, MA, USA), concentrated on a $15 \times 15 \mathrm{~cm}$ positively charged nylon membrane (Boehringer Mannheim, Indianapolis, IN, USA) and fixed to the membrane by baking it at $120^{\circ} \mathrm{C}$ for $20 \mathrm{~min}$. The membrane was placed in a Miniblotter 45 (Immunetics, Cambridge, MA, USA) with the lanes of DNA at $90^{\circ}$ to the lanes of the device. Digoxigenin-labelled whole genomic DNA probes for 40 bacterial species were hybridized in individual lanes of the Miniblotter. After hybridization, the membranes were washed at high stringency and the DNA probes were detected using the antibody to digoxigenin conjugated with alkaline phosphatase and chemiluminescence detection using the scanner G:Box iChemi XL (Syngene/ USA). The last two lanes in each run contained standards at concentrations of $10^{5}$ and $10^{6}$ cells of each species and the signals were converted to absolute counts by comparing them with the controls in each membrane. The sensitivity of the assay was adjusted to allow detection of $10^{4}$ cells of each bacterial species.

\section{Primary and secondary outcome variables}

The primary outcome variable was the difference between groups for the mean number of total CFUs in all plates (all locations). Secondary outcome variables were differences among groups for the following parameters: mean number of total CFUs in plates positioned on the clinician forehead, volunteer's chest and support board; mean proportion of the microbial complexes, as well as the mean percent reduction in CFUs in the $\mathrm{CPC}+\mathrm{Zn}+\mathrm{F}$ and $\mathrm{CHX}$ groups in comparison with the Water and No Rinsing groups.

\section{Statistical analysis}

The total number of CFUs in the plates placed on the support board, clinician and volunteer, as well as all locations grouped were computed for each volunteer and then averaged in each group. 
For the support board, the mean number of CFUs of the three plates per volunteer was computed. For the Checkerboard DNA-DNA hybridization analysis, the mean levels of each bacterial species was averaged within each participant and then across participants in each of the four groups. After this, the percentage of the total DNA probe counts (proportions) was determined per volunteer, and averaged across volunteers within each group. In addition, the proportions of the species belonging to the six complexes and the "other" group defined by Socransky et al. ${ }^{30}$ were added to generate the proportion of each complex per group. The significance of differences between groups for the microbial data and for age were determined by Kruskall-Wallis and Dunn tests. Chi-square test was used to compare the differences in the frequency of gender and smoking status. The level of significance was set at $5 \%$.

\section{Results}

This RCT was conducted between February and April of 2015. Figure 2 presents the flow diagram of the study. Sixty volunteers participated in the study. Table 1 presents the demographic characteristics of the volunteers according to the different experimental groups. No statistically significant differences were observed among the four groups at the time of data collection. No volunteer reported any adverse events associated with the use of the mouthwashes evaluated.

No bacterial growth was detected in the agar plates located in the dental office before the experiment started (environmental contamination). The mean CFUs in different locations according to the experimental groups are presented in Figure 3. The aerosol/splatter from volunteers that rinsed with $\mathrm{CPC}+\mathrm{Zn}+\mathrm{F}$ or $\mathrm{CHX}$ harbored statistically significantly $(\mathrm{p}<0.05)$ lower CFUs counts than those who rinsed with water or who did

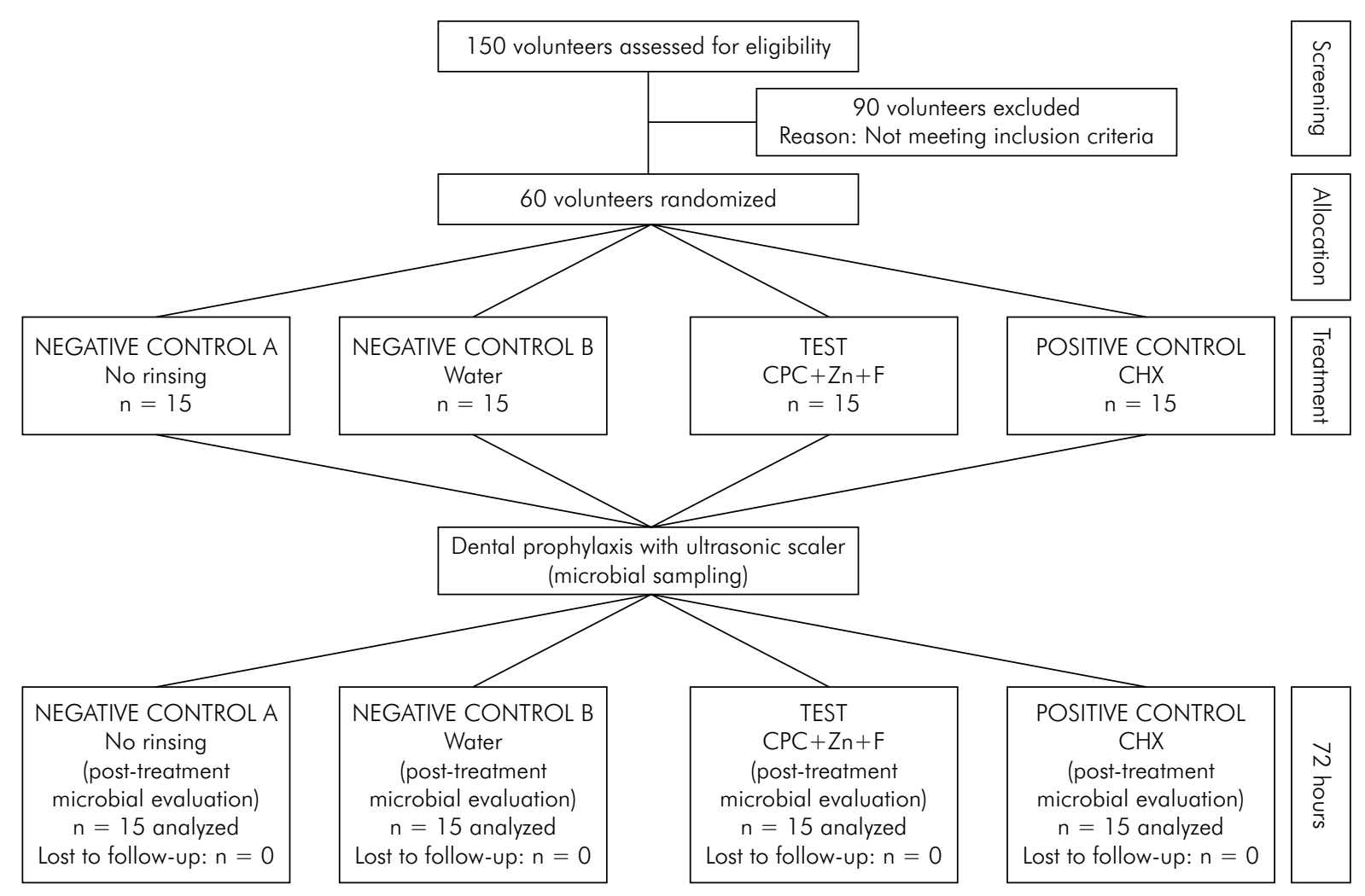

CPC: cetylpyridinium chloride; Zn: zinc lactate; F: sodium fluoride; CHX: chlorhexidine digluconate.

Figure 2. Flow chart of the study design. 
not rinse. This occurred in the agar plates placed on the clinician's forehead, volunteer's chest and when all plates were evaluated together. However, when the plates placed on the support board were evaluated, this difference was not statistically significant $(p>0.05)$ between the Water group and the other two mouthwash $(\mathrm{CPC}+\mathrm{Zn}+\mathrm{F}$ or $\mathrm{CHX})$ groups.

Table 2 shows the mean decrease in CFUs in the $\mathrm{CPC}+\mathrm{Zn}+\mathrm{F}$ and $\mathrm{CHX}$ groups compared with No Rinsing and Water groups. When all locations were considered together, the aerosols/splatters from the $\mathrm{CPC}+\mathrm{Zn}+\mathrm{F}$ and $\mathrm{CHX}$ groups showed, respectively, $70 \%$ and $77 \%$ fewer CFUs than the group that did not rinse, and $61 \%$ and $70 \%$ than those from the group that rinsed with water. Figure 4 presents the mean proportions of DNA probe counts of the 40 subgingival species evaluated by Checkerboard DNA-DNA Hybridization technique. No statistically significant $(p>0.05)$ differences between groups were observed for any individual proportion of the species tested. When the bacterial species were grouped into "Microbial Complexes" (Figure 5), the data showed that aerosols/splatters from $\mathrm{CPC}+\mathrm{Zn}+\mathrm{F}$ and $\mathrm{CHX}$ groups had a lower proportion of bacterial species from the orange complex (41.4\% and 39.1\%, respectively) when compared with aerosols/splatter from No rinsing and Water groups (51.1\% and $47.1 \%$, respectively).

\section{Discussion}

The results of the present study showed that oral aerosol/splatter from subjects who rinsed with a mouthwash containing $0.075 \%$ CPC, $0.28 \% \mathrm{Zn}$ and $0.05 \% \mathrm{~F}$, before receiving an ultrasonic prophylaxis, harbored a significantly lower bacterial content that from subjects who did not rinse or rinsed with water.
This pre-procedural mouthwash was as effective as the CHX positive control mouthwash in reducing viable bacteria in dental aerosols/splatter. These results are in agreement with those of a previous study that evaluated a mouthwash containing CPC. ${ }^{3}$

According to our results, the clinician was the person who most benefited from the pre-procedural rinsing. The blood agar plates positioned on the clinician's forehead, from the volunteers who rinsed with $\mathrm{CPC}+\mathrm{Zn}+\mathrm{F}$ or $\mathrm{CHX}$, harbored, $89 \%$ and $94 \%$ fewer CFUs respectively, than the plates from the volunteers

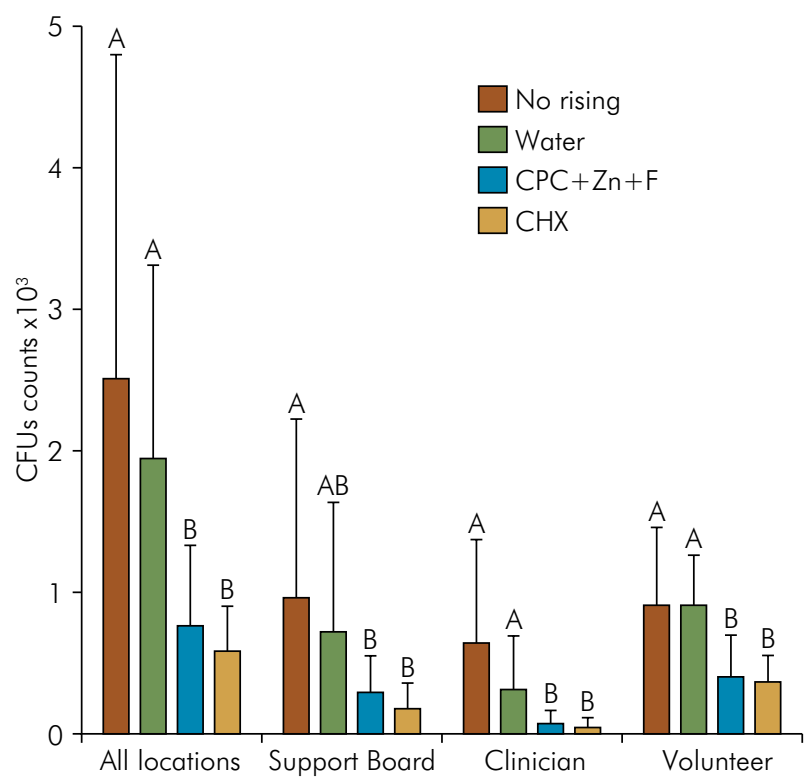

CPC: cetylpyridinium chloride; $\mathrm{Zn}$ : zinc lactate; F: sodium fluoride; $\mathrm{CHX}$ : chlorhexidine digluconate; CFUs: colony-forming units.

Figure 3. Bar chart of the mean total colony-forming units (CFUs) in the volunteer, clinician, support board and all locations according to experimental groups. The significance of differences among groups was assessed using Kruskal-Wallis and Dunn test (different capital letters indicate significant differences between test and control groups, $p<0.05)$.

Table 1. Demographic characteristics $(n=60)$.

\begin{tabular}{lccccc}
\hline \multirow{2}{*}{ Variable } & \multicolumn{4}{c}{ Experimental groups } \\
\cline { 2 - 5 } & No rinsing $(\mathrm{n}=15)$ & Water $(\mathrm{n}=15)$ & $\mathrm{CPC}+\mathrm{Zn}+\mathrm{F}(\mathrm{n}=15)$ & $\mathrm{CHX}(\mathrm{n}=15)$ & $\mathrm{p}$-value \\
\hline Age (mean years $\pm \mathrm{SD})$ & $46.27 \pm 6.63$ & $36.13 \pm 8.71$ & $45.47 \pm 11.79$ & $41.40 \pm 10.93$ & $\mathrm{p}>0.05$ \\
Gender (female/male) & $7 / 8$ & $9 / 6$ & $10 / 5$ & $10 / 5$ & $\mathrm{p}>0.05$ \\
Smokers (yes/not) & $0 / 15$ & $0 / 15$ & $1 / 14$ & $1 / 14$ & $\mathrm{p}>0.05$ \\
\hline
\end{tabular}

The significance of differences among groups for gender and percentage of smokers was assessed using the Chi-square test and for mean age was assessed using Kruskal-Wallis test. CPC: cetylpyridinium chloride; Zn: zinc lactate; F: sodium fluoride; CHX: chlorhexidine digluconate; SD: standard deviation. 
who did not rinse. This represents important protection for the dentist and dental hygienists, who are the main targets of the microorganisms generated during oral procedures. ${ }^{6}$ It is important to emphasize that the dental/surface barriers, the methods most commonly used to minimize cross-infection in the dental office, do not reduce the levels of microorganisms in the environment. Pre-procedural rinsing provides a viable

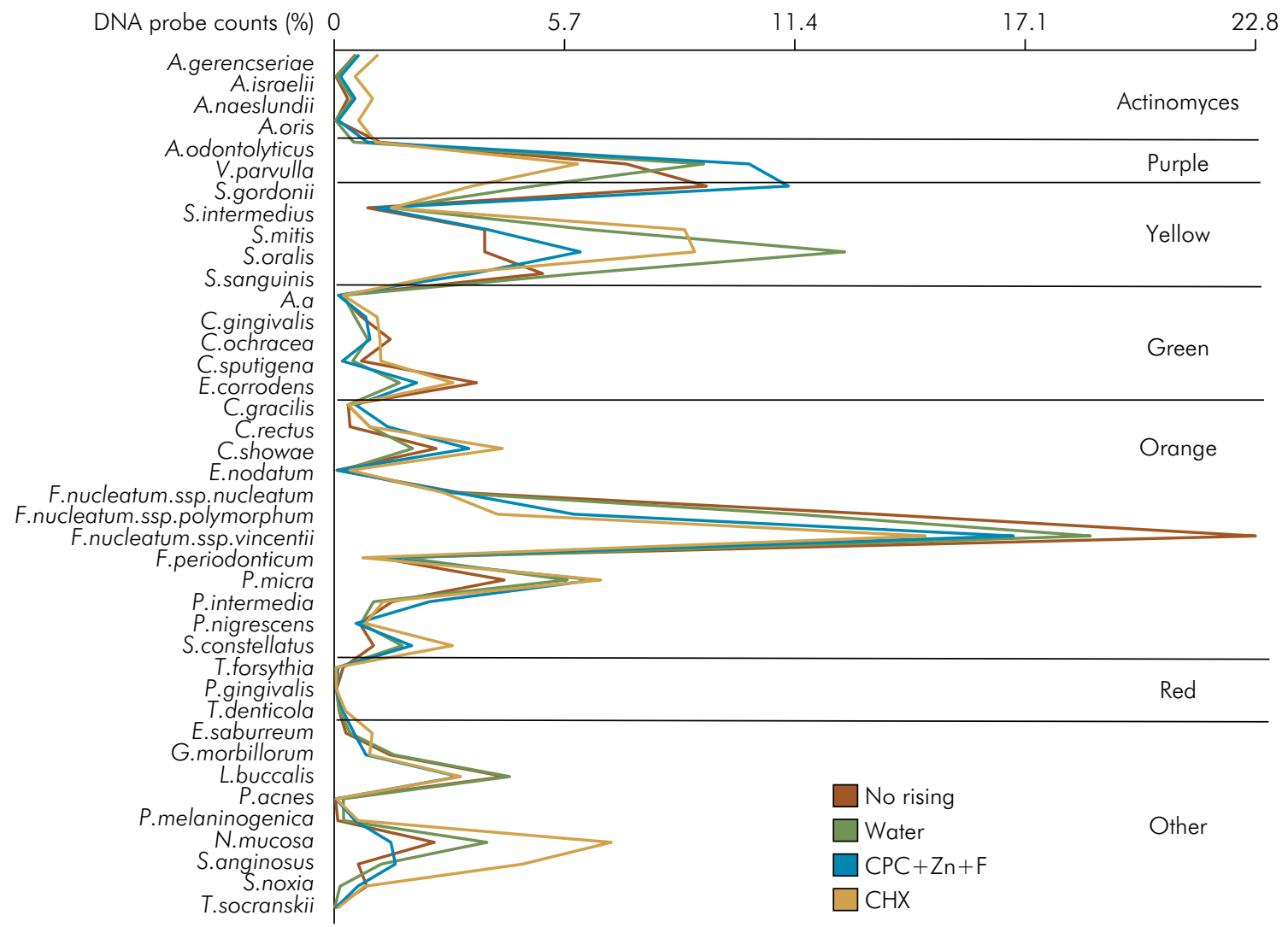

CPC: cetylpyridinium chloride; Zn: zinc lactate; F: sodium fluoride; CHX: chlorhexidine digluconate; \%: percentage.

Figure 4. Mean percentage of DNA probes counts of 40 subgingival species in the four experimental groups. The species were ordered according to the microbial complexes described by Socransky et al. ${ }^{30}$ The proportion that each species was determined for each participant and then averaged in each experimental group. The significance of differences among the four groups was assessed using Kruskal-Wallis test ( $p<0.05$, adjusted for multiple comparisons).
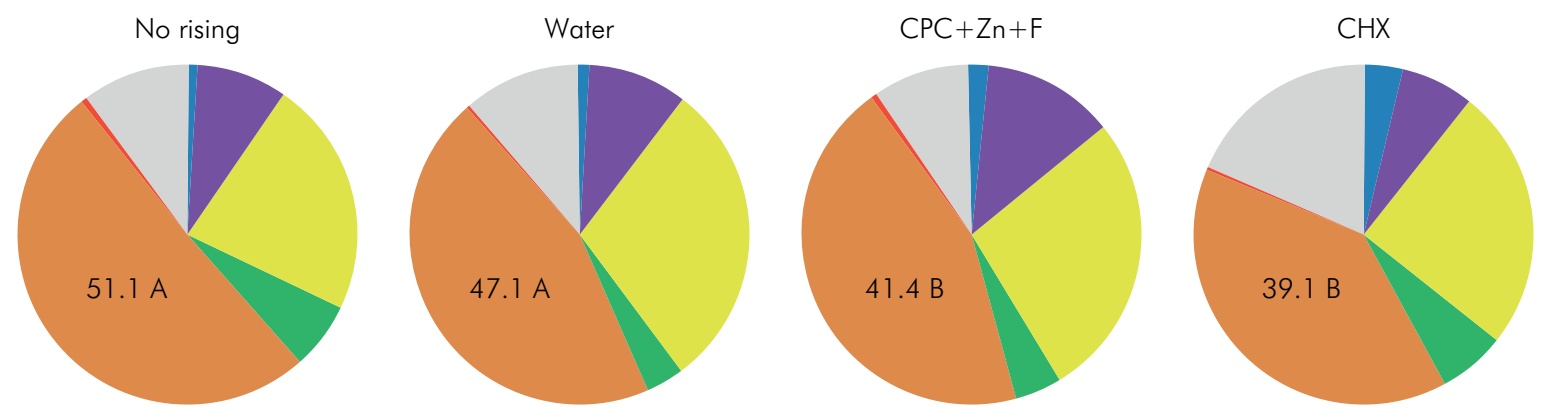

CPC: cetylpyridinium chloride; $\mathrm{Zn}$ : zinc lactate; F: sodium fluoride; CHX: chlorhexidine digluconate.

Figure 5. Pie charts of the mean proportion of each microbial complex in the four experimental groups. The colors represent different microbial complexes described by Socransky et al. ${ }^{30}$ The significance of differences among experimental groups was assessed using the Kruskal-Wallis and Dunn tests (different capital letters indicate significant differences between groups, $\mathrm{p}<0.05$ ). 
Table 2. Mean percentage of CFUs reduction (average values) in the $\mathrm{CHX}$ and $\mathrm{CPC}+\mathrm{Zn}+\mathrm{F}$ groups compared with the No Rinsing and Water groups considering all evaluated locations.

\begin{tabular}{lcccc}
\hline \multirow{2}{*}{ Variable } & \multicolumn{4}{c}{ Locations (\% of CFUs reduction) } \\
\cline { 2 - 5 } & Clinician & Volunteers & Board & All \\
\hline CHX versus No rinsing & 94 & 60 & 81 & 77 \\
CPC + Zn+F versus No rinsing & 89 & 55 & 70 & 70 \\
CHX versus Water & 87 & 60 & 75 & 70 \\
CPC + Zn+F versus Water & 78 & 55 & 59 & 61 \\
\hline
\end{tabular}

CFUs: colony-forming units; CPC: cetylpyridinium chloride; Zn: zinc lactate; F: sodium fluoride; CHX: chlorhexidine digluconate; \%: percentage.

mean of protection because these barriers, such as gloves, masks and glasses may have openings, smaller pores or defects, through which bacteria can pass. Furthermore, the aerosol particles may remain in the environment for up to 4 hours after a procedure ${ }^{31}$ and normally, the clinician and patients remove the protective barriers shortly after completion of the procedure. Therefore, the risk of airway contamination by these microorganisms even after the completion of the appointment is high. ${ }^{1}$ Thus, minimizing the quantity of microorganisms in the oral cavity before the aerosol/splatter is generated is essential to reduce the risk of cross-infection in the dental environment.

In addition, the pre-procedural rinsing also represented a major benefit for the patients. In the present study, high bacterial counts, which reached an average of $\approx 1.000$ CFUs in the Water and No Rinsing groups, were observed on the blood agar plates positioned on the volunteer's chest. The plates positioned on the chest of the volunteers who pre-rinsed with $\mathrm{CPC}+\mathrm{Zn}+\mathrm{F}$ showed $55 \%$ fewer bacterial colonies than those who did not rinse or who rinsed with water, suggesting a major effect of this solution in reducing the levels of bacteria in the patient's oral cavity. A similar effect was observed for the CHX group, which showed $60 \%$ fewer bacterial colonies than the Water and No Rinsing groups. These are relevant items of information for the dental practitioner, as they may benefit the patients in several ways during dental procedures, such as for example, by reducing the odds of bacterial spread to other areas of the body, such as the eyes through aerosol, ${ }^{11,32}$ or even into the lungs though inhalation. ${ }^{33}$

The previous studies that have evaluated the effects of different antiseptics in reducing aerosol contamination, have recommended $\mathrm{CHX}$ as the gold standard. . $^{3,4,3,34,35,36}$
$\mathrm{CHX}$ as a pre-procedural rinse has been compared with other antiseptics, such as essential oils, ${ }^{13}$ povidone iodine and ozone, ${ }^{36}$ tea tree oil ${ }^{35}$ a solution containing different types of herb extracts ${ }^{4}$ and CPC. ${ }^{3} \mathrm{CHX}$ was shown to be more effective than most of these other antimicrobial agents. Only CPC has shown to be as effective as $\mathrm{CHX}$ in reducing the content of bacteria in dental aerosols, ${ }^{3}$ results that corroborate those reported in the present study for $0.075 \% \mathrm{CPC}+\mathrm{Zn}+\mathrm{F}$. An additional advantage for CPC compared with $\mathrm{CHX}$ is its lower $\operatorname{cost}^{37}$ and the reduced chance of patient intolerance to the product..$^{38}$ Therefore, the main strength of this study is that it is the first RCT to determine the efficacy of a new formulation containing CPC in reducing oral bacterial load in the patient's mouth and consequently, in the aerosols, as well as determining the microbial composition of these aerosols.

The analysis of the microbial composition showed statistically significantly higher proportions of putative pathogens from the orange complex ${ }^{30}$ in the aerosols/splatters from the Water and No Rinsing groups in comparison with those from the CPC $+\mathrm{Zn}+\mathrm{F}$ and $\mathrm{CHX}$ groups, in agreement with a previous study. ${ }^{3}$ This represents an additional beneficial effect of the pre-rinsing, since certain species from the orange complex, such as the Fusobacterium species, may be associated with the etiology of ophthalmic and respiratory infections. ${ }^{32,33}$

One limitation of the present study is that it presents results for a single dental procedure, prophylaxis with an ultrasonic scaler that has been shown to have a great potential for aerosol generation in the dental office. . $^{1,3,4,5,39}$ However, other dental procedures can also generate a large amount of aerosol with infectious components launched into the dental environment, such as the air turbine handpiece, ${ }^{6,7}$ air-water from a three-way syringe $^{8}$ and sodium bicarbonate jet. ${ }^{39}$ Therefore, one 
could assume that rinsing with CPC would yield similar benefits if used before the majority of dental procedures.

\section{Conclusion}

In conclusion, the results of this study showed that a mouthwash containing $0.075 \%$ CPC, $0.28 \%$ zinc lactate and $0.05 \%$ sodium fluoride as a pre-procedural

\section{References}

1. Rivera-Hidalgo F, Barnes JB, Harrel SK. Aerosol and splatter production by focused spray and standard ultrasonic inserts. J Periodontol. 1999;70(5):473-7. https://doi.org/10.1902/jop.1999.70.5.473

2. Timmerman MF, Menso L, Steinfort J, Winkelhoff AJ, Weijden GA. Atmospheric contamination during ultrasonic scaling. J Clin Periodontol. 2004;31(6):458-62. https://doi.org/10.1111/j.1600-051X.2004.00511.x

3. Feres M, Figueiredo LC, Faveri M, Stewart B, Vizio $\mathrm{W}$. The effectiveness of a preprocedural mouthrinse containing cetylpyridinium chloride in reducing bacteria in the dental office. J Am Dent Assoc. 2010;141(4):415-22. https://doi.org/10.14219/jada.archive.2010.0193

4. Gupta G, Mitra D, Ashok KP, Gupta A, Soni S, Ahmed $S$ et al. Efficacy of preprocedural mouth rinsing in reducing aerosol contamination produced by ultrasonic scaler: a pilot study. J Periodontol. 2014;85(4):562-8. https://doi.org/10.1902/jop.2013.120616

5. Veena HR, Mahantesha S, Joseph PA, Patil SR, Patil SH. Dissemination of aerosol and splatter during ultrasonic scaling: a pilot study. J Infect Public Health. 2015;8(3):260-5. https://doi.org/10.1016/j.jiph.2014.11.004

6. Bentley CD, Burkhart NW, Crawford JJ. Evaluating spatter and aerosol contamination during dental procedures. J Am Dent Assoc. 1994;125(5):579-84. https://doi.org/10.14219/jada.archive.1994.0093

7. Toroğlu MS, Haytaç MC, Köksal F. Evaluation of aerosol contamination during debonding procedures. Angle Orthod. 2001;71(4):299-306. https://doi.org/10.1043/00033219(2001)071<0299:EOACDD>2.0.CO;2

8. Souza-Gugelmin MC, Lima CD, Lima SN, Mian H, Ito IY. Microbial contamination in dental unit waterlines. Braz Dent J. 2003;14(1):55-7. https://doi.org/10.1590/S0103-64402003000100010

9. Leggat PA, Kedjarune U. Bacterial aerosols in the dental clinic: a review. Int Dent J. 2001;51(1):39-44. https://doi.org/10.1002/j.1875-595X.2001.tb00816.x mouthwash was effective in reducing bacterial species present in viable oral aerosols during prophylaxis with ultrasonic instruments.

\section{Acknowledgments}

The research described in this article was supported by Colgate Palmolive Company (Piscataway, NJ, USA) and Latin America Oral Health Association (LAOHA).

10. Cochran MA, Miller $\mathrm{CH}$, Sheldrake MA. The efficacy of the rubber dam as a barrier to the spread of microorganisms during dental treatment. J Am Dent Assoc. 1989;119(1):141-4. https://doi.org/10.14219/jada.archive.1989.0131

11. Nejatidanesh F, Khosravi Z, Goroohi H, Badrian H, Savabi O. Risk of contamination of different areas of dentist's face during dental practices. Int J Prev Med. 2013;4(5):611-5.

12. Kanjirath PP, Coplen AE, Chapman JC, Peters MC, Inglehart MR. Effectiveness of gloves and infection control in dentistry: student and provider perspectives. J Dent Educ. 2009;73(5):571-80.

13. Logothetis DD, Martinez-Welles JM. Reducing bacterial aerosol contamination with a chlorhexidine gluconate pre-rinse. J Am Dent Assoc. 1995;126(12):1634-9. https://doi.org/10.14219/jada.archive.1995.0111

14. Jones CG. Chlorhexidine: is it still the gold standard? Periodontol. 2000. 1997;15(1):55-62. https://doi.org/10.1111/j.1600-0757.1997.tb00105.x

15. Thomas E. Efficacy of two commonly available mouth rinses used as preprocedural rinses in children. J Indian Soc Pedod Prev Dent. 2011;29(2):113-6. https://doi.org/10.4103/0970-4388.84682

16. Varoni E, Tarce M, Lodi G, Carrassi A. Chlorhexidine (CHX) in dentistry: state of the art. Minerva Stomatol. 2012;61(9):399-419.

17. Yengopal V. The use of essential oil mouthwashes as preprocedural rinses for infection control. SADJ. 2004;59(6):247-8.

18. Costa X, Laguna E, Herrera D, Serrano J, Alonso B, Sanz M. Efficacy of a new mouth rinse formulation based on $0.07 \%$ cetylpyridinium chloride in the control of plaque and gingivitis: a 6-month randomized clinical trial. J Clin Periodontol. 2013;40(11):1007-15. https://doi.org/10.1111/jcpe.12158

19. Pandit S, Cai JN, Jung JE, Lee YS, Jeon JG. Effect of brief cetylpyridinium chloride treatments during early and mature cariogenic biofilm formation. Oral Dis. 2015;21(5):565-71. https://doi.org/10.1111/odi.12312 
20. Department of Health and Human Service (US).

Food and Drug Administration. 21 CFR Part 356.

Oral health care drug products for over-the-counter human use; anti-gingivitis/anti-plaque drug products; establishment of a monograph; proposed rules. Federal Register 2003 May 29[cited 2016 Feb 1]. Available from: https://federalregister.gov/a/03-12783

21. Kang JH, Jang YJ, Kim DJ, Park JW. Antimicrobial effectiveness of cetylpyridinium chloride and zinc chloride-containing mouthrinses on bacteria of halitosis and peri-implant disease. Int J Oral Maxillofac Implants. 2015;30(6):1341-7. https://doi.org/10.11607/jomi.3824

22. Mendes L, Coimbra J, Pereira AL, Resende M, Pinto MG. Comparative effect of a new mouthrinse containing chlorhexidine, triclosan and zinc on volatile sulphur compounds: a randomized, crossover, double-blind study. Int J Dent Hyg. 2016;14(3):202-8. https://doi.org/10.1111/idh.12132

23. Giertsen E. Effects of mouthrinses with triclosan, zinc ions, copolymer, and sodium lauryl sulphate combined with fluoride on acid formation by dental plaque in vivo. Caries Res. 2004;38(5):430-5. https://doi.org/10.1159/000079623

24. Kjaerheim V, Skaare A, Barkvoll P, Rölla G. Antiplaque, antibacterial, and anti-inflammatory properties of triclosan mouthrinses in combination with zinc citrate or polyvinylmethylether maleic acid (PVM-MA) copolymer. Eur J Oral Sci. 1996;104(5-6):529-34. https://doi.org/10.1111/j.1600-0722.1996.tb00137.x

25. Lang C, Murgia C, Leong M, Tan LW, Perozzi G, Knight D, et al. Anti-inflammatory effects of zinc and alterations in zinc transporter mRNA in mouse models of allergic inflammation. Am J Physiol Lung Cell Mol Physiol. 2007;292(2):L577-84. https://doi.org/10.1152/ajplung.00280.2006

26. Erovic Ademovski S, Lingström P, Renvert S. The effect of different mouth rinse products on intra-oral halitosis. Int J Dent Hyg. 2016;14(2):117-23. https://doi.org/10.1111/idh.12148

27. Maggio B, Guibert RG, Mason SC, Karwal R, Rees GD, Kelly $S$ et al. Evaluation of mouthrinse and dentifrice regimens in an in situ erosion remineralisation model. J Dent. 2010;18 Supple 3:S37-44. https://doi.org/10.1016/S0300-5712(11)70007-0

28. Socransky SS, Smith C, Martin L, Paster BJ, Dewhirst FE, Levin AE. "Checkerboard” DNA-DNA hybridization. Biotechniques. 1994;17(4):788-92.
29. Mestnik MJ, Feres M, Figueiredo LC, Duarte PM, Lira EA, Faveri M. Short-term benefits of the adjunctive use of metronidazole plus amoxicillin in the microbial profile and in the clinical parameters of subjects with generalized aggressive periodontitis. J Clin Periodontol. 2010;37(4):353-65. https://doi.org/10.1111/j.1600-051X.2010.01538.x

30. Socransky SS, Haffajee AD, Cugini MA, Smith C, Kent RL, Jr. Microbial complexes in subgingival plaque. J Clin Periodontol. 1998;25(2):134-44. https://doi.org/10.1111/j.1600-051X.1998.tb02419.x

31. Grenier D. Quantitative analysis of bacterial aerosols in two different dental clinic environments. Appl Environ Microbiol. 1995;61(8):3165-8.

32. Arat YO, Shetlar DJ, Rose JE. Blindness from septic thrombophlebitis of the orbit and cavernous sinus caused by Fusobacterium nucleatum. Arch Ophthalmol. 2004;122(4):652-4. https://doi.org/10.1001/archopht.122.4.652

33. Bhattacharya S, Livsey SA, Wiselka M, Bukhari SS. Fusobacteriosis presenting as community acquired pneumonia. J Infect. 2005;50(3):236-9. https://doi.org/10.1016/j.jinf.2003.11.007

34. Reddy S, Prasad MG, Kaul S, Satish K, Kakarala S, Bhowmik N. Efficacy of $0.2 \%$ tempered chlorhexidine as a pre-procedural mouth rinse: A clinical study. J Indian Soc Periodontol. 2012;16(2):213-7. https://doi.org/10.4103/0972-124X.99264

35. Shetty SK, Sharath K, Shenoy S, Sreekumar C, Shetty RN, Biju T. Compare the effcacy of two commercially available mouthrinses in reducing viable bacterial count in dental aerosol produced during ultrasonic scaling when used as a preprocedural rinse. J Contemp Dent Pract. 2013;14(5):848-51. https://doi.org/10.5005/jp-journals-10024-1414

36. Kaur R, Singh I, Vandana KL, Desai R. Effect of chlorhexidine, povidone iodine, and ozone on microorganisms in dental aerosols: randomized double-blind clinical trial. Indian J Dent Res. 2014;25(2):160-5. https://doi.org/10.4103/0970-9290.135910

37. Slots J. Low-cost periodontal therapy. Periodontol 2000. 2012;60(1):110-37. https://doi.org/10.1111/j.1600-0757.2011.00429.x

38. Keni NN, Aras MA, Chitre V. Chlorhexidine allergy due to topical application. Indian J Dent Res. 2012;23(5):674-6. https://doi.org/10.4103/0970-9290.107393

39. Legnani P, Checchi L, Pelliccioni GA, D'Achille C. Atmospheric contamination during dental procedures. Quintessence Int. 1994;25(6):435-9. 